\title{
Fecal Markers of Environmental Enteric Dysfunction and their Relation to Faltering Growth in a Sample of Egyptian Children
}

\author{
Maged A. El Wakeel ${ }^{1}$, Ghada M. El-Kassas ${ }^{1}$, Gihan Fouad Ahmed ${ }^{2}$, Walaa H. Ali ${ }^{1 *}$, Eman Mohamed Elsheikh, \\ Salwa Refat El-Zayat ${ }^{3}$, Nevein N. Fadl ${ }^{3}$, Iman H. Kamel ${ }^{1}$, Thanaa M. Rabah ${ }^{4}$ \\ ${ }^{1}$ Department of Child Health, National Research Centre, Giza, Egypt; ${ }^{2}$ Department of Pediatrics, National Nutrition Institute, \\ Cairo, Egypt; ${ }^{3}$ Department of Medical Physiology, National Research Centre, Giza, Egypt; ${ }^{4}$ Department of Community Medicine \\ Research, National Research Centre, Giza, Egypt
}

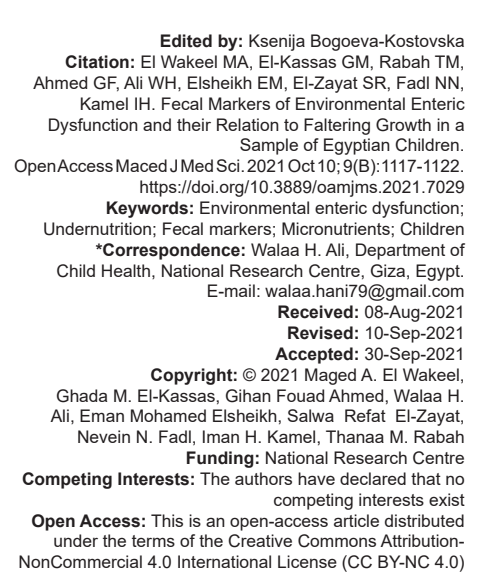

\section{Introduction}

Chronic malnutrition is a long-term health condition that has threatening effects on children health. Undernutrition (stunting, wasting, and micronutrient deficiency) is considered to be responsible for $45 \%$ of all deaths among children under 5 years [1].

The Egyptian Health Survey which was conducted in 2014 revealed that about $16 \%$ of Egyptian children $<5$ years are stunted, $4 \%$ are wasted, and $8 \%$ are underweight [2]. Stunted growth in developing countries may occur as a result of chronic nutrient deficiencies, recurrent infections, chronic inflammatory disorders including environmental enteric dysfunction (EED), as well as other hormonal and metabolic disorders [3]. Stunting is usually accompanied by an increase in severity and duration of infections as pneumonia and infectious diarrhea in children [4]. Moreover, faltering growth which affects children during their early life is extremely critical, being not fully reversible and causing permanent consequences.
Improving growth in children with growth impairment is a global target, so interventions should be done as early as possible when linear growth has a great response to them [5].

EED is a subclinical disorder affecting the small intestine that may occur due to exposure to environmental pathogens and toxins, mainly in children living in poor water, hygiene, and sanitation conditions. This disorder is usually associated with linear growth retardation [6]. Growth failure in EED may be worsened by the occurrence of acute malnutrition as a result of recurrent gastrointestinal and pulmonary infections [7].

The gold standard for diagnosis of EED is histopathology for small intestinal biopsy via invasive endoscopy, but this procedure cannot be applied at the population level for screening such a wide-spreading condition. Hence, less invasive markers are used to detect intestinal inflammation and increased intestinal permeability [8]. The most commonly used test for EED detection up till now is lactulose: mannitol ( $L$ : $M)$ test, but other sugars such as xylose and rhamnose can be also used [6]. 
Myeloperoxidase (MPO) and Neopetrin (NEO) are fecal markers that reflect gut inflammation. MPO is a specific biomarker for polymorphonuclear leukocyte activity. It reflects intestinal inflammation in Crohn's disease or ulcerative colitis. NEO results from the degradation of cyclic guanosine monophosphate reflecting intestinal epithelium inflammatory immune response [8]. Alpha-1-anti trypsin (AAT) is a classic biomarker for detecting protein losing enteropathy, when it is present in stool; it indicates an increased intestinal permeability and protein loss [4].

Decreased levels of micronutrients may have a key role in EED, however in such conditions, it is not easy to determine whether EED causes this decrease in micronutrients level (through malabsorption) or if micronutrients deficiency causes EED through inability to maintain a healthy intestinal lining. Zinc can help intestinal mucosa recovery after diarrhea [9].

This study was intended to detect the value of fecal biomarkers of intestinal epithelial damage AAT and intestinal inflammation (MPO and NEO), also to quantify their association with faltering growth in stunted and underweight children.

\section{Subjects and Methods}

The current study is a case-control study that was conducted at National Research Centre from December 2019 to April 2021 as a part of ongoing in-house project No. 12060128.

\section{Inclusion criteria}

105 children (aged from 1 to 10 years), who are underweight (weight for age z-score [WAZ] <-2] and stunted (height for age z-score [HAZ] <-2) (based on the World Health Organization Child Growth Standards) were included in the study. Both sexes were represented (males and females). These children were recruited from the nutrition-Immuno clinic in The Medical Research Centre of Excellence.

\section{Exclusion criteria}

Chronic debilitating illness, including (congenital heart disease, chronic renal problems, neurological or developmental disabilities) was excluded from the study. Recent history of diarrhea or hematochezia was excluded from the study. Heavy parasitic infestations at time of inclusion were excluded by stool analysis.

\section{Control group}

100 children (age and sex matched) of normal body weight and height, having $\mathrm{HAZ}$ and WAZ better than -1. All children involved in this study had the following: Complete history taking, thorough clinical examination laying stress on signs of anemia and vitamins deficiency. Anthropometric measurements were done according to techniques described in the Anthropometric Standardization Reference Manual [10]. Children were weighed (in $\mathrm{kg}$ ) using a calibrated Seca scale to the nearest $0.1 \mathrm{~kg}$ (Seca, Hamburg, Germany), while height (in $\mathrm{cm}$ ) was measured using a Seca 225 stadiometer to the nearest $0.1 \mathrm{~cm}$, with the children dressed in light clothes and without shoes [11], [12]. All anthropometric measurements were taken triplicate and averaged. Body mass index (BMI) for age was calculated according to formula BMI= (Weight $/$ [Height in $]^{2}$ ) [13].

\section{Laboratory investigations}

Three milliliters of venous samples were withdrawn from each child, and then the samples were divided into two parts. The first part was added to a tube containing EDTA for complete blood count determination using an automated analyzer (Cel- dyn.3500; Abbott Diagnostics, Abbott Park; IL). The second part was put in a serum separator then centrifuged and stored at $-80^{\circ} \mathrm{C}$ for later measurement of zinc and iron. Serum zinc was measured by colorimetric method with 5-Brom- PAPS. Serum iron was quantified using the colorimetric $\mathrm{CAB}$ method. Both kits were obtained from Egyptian Company for Biotechnology (S.A.E) Obor City industrial area, block 20008, Cairo, Egypt. Stool samples were collected without fixative and frozen at $-70^{\circ} \mathrm{c}$ before testing. Specimens were processed at dilution of 1:500, and then were evaluated for MPO, NEO, and $\alpha 1$-antitrypsin using commercially available ELISA kits (SunLong Biotch Co., LTD). The MPO kit detection range was $(0.2-10 \mathrm{ng} / \mathrm{ml})$ catalog number: SL1230Hu. The detection range of the NEO kit was (3-100 pg/ml) catalog number: $\mathrm{SL} 2303 \mathrm{Hu}$. The detection range of the $\alpha 1$-antitrypsin kit was $(0.5-40 \mathrm{ng} / \mathrm{ml})$ catalog number: SL1847Hu.

\section{Ethical approval}

The present study has been approved by Medical Research Ethical Committee of the National Research Centre, Egypt (the approval number was 19/227). A written informed consent for all participants was collected from their parents after explaining the purpose and methodology of the study.

\section{Statistical analysis}

All test data were converted and manipulated using SPSS software program version 20.0. Data were analyzed, mean and standard deviation or median were calculated as regarding quantitative data, while qualitative data were presented by number and percent. 
Comparisons between cases and controls were done according to anthropometric measures and laboratory results. The quantitative data were compared and t-test was applied for normally distributed data and MannWhitney test was applied for non-parametric data and $\mathrm{p}$-value was established to determine the statistically significant difference between the two groups. Pearson's correlation between anthropometric and laboratory data was done and Pearson's correlation coefficient was computed and $p$-value was established. Multiple Linear regression was done to determine factors mostly affecting weight $Z$ score and Height $Z$ score among cases. The difference between groups was considered statistically significant when $p<0.05$.

\section{Results}

A total number of 205 children were included in the present study. They were divided into two groups: Case group (105 underweight and stunted children) and control group (100 children of normal weight and height). The characteristics of all studied children are depicted in Table 1.

Table 1: Comparison between cases and controls according to age, sex, and anthropometric measures

\begin{tabular}{llll}
\hline Variable & $\begin{array}{l}\text { Cases, } \mathrm{n}=105, \\
\text { Mean } \pm \mathrm{SD}\end{array}$ & $\begin{array}{l}\text { Controls, } \mathrm{n}=100, \\
\text { Mean } \pm \mathrm{SD}\end{array}$ & p-value \\
\hline $\begin{array}{l}\text { Age (months) } \\
\text { Sex (no. \%) }\end{array}$ & $79.71 \pm 34.3$ & $79.33 \pm 39.5$ & 0.85 \\
$\quad$ Male & $47(44.8)$ & $46(46.0)$ & 0.859 \\
$\quad$ Female & $58(55.2)$ & $54(54.0)$ & \\
Weight $(\mathrm{Kg})$ & $17.88 \pm 5.7$ & $25.18 \pm 11.0$ & $<0.001^{*}$ \\
Weight Z score & $-2.08 \pm 0.8$ & $0.4 \pm 0.4$ & $<0.001^{*}$ \\
Height $(\mathrm{cm})$ & $107.94 \pm 15.9$ & $119.91 \pm 21.3$ & $<0.001^{*}$ \\
Height Z score & $-2.18 \pm 0.8$ & $0.44 \pm 0.4$ & $<0.001^{*}$ \\
BMl & $15.14 \pm 1.5$ & $16.71 \pm 1.5$ & $<0.001^{*}$ \\
BMl Z score & $-0.74 \pm 1.2$ & $0.34 \pm 0.4$ & $<0.001^{*}$ \\
Arm circumference $(\mathrm{cm})$ & $16.56 \pm 1.8$ & $17.73 \pm 2.0$ & $<0.001^{*}$ \\
\hline${ }^{*}$ p $<0$ 05 significant & & &
\end{tabular}

Non-significant difference was observed between our two studied groups regarding sex and age. The cases were $44.8 \%$ males and $55.2 \%$ females, where the controls were $46 \%$ males and $54 \%$ females $(p=0.859)$. The mean age of the cases and controls was $79.71 \pm 37.3$ months and $79.33 \pm 39.5$ months, respectively, $(p=0.85)$, so both groups were sex- and age-matched. A highly significant difference between studied groups regarding anthropometric measurements (weight, height, BMI, WAZ score, HAZ score, BMI Z score, and arm circumference) was observed $(p<0.001)$.

The results in Table 2 represented the levels of serum zinc and iron which displayed a significant decline in cases in comparison to controls ( $p<0.001)$.

Table 3 illustrated the results of fecal markers ( $\alpha 1$-antitrypsin, NEO, and MPO) that revealed a significant difference between cases and controls regarding $\alpha 1$-antitrypsin and NEO $(p=0.012,0.021$,
Table 2: Comparison between cases and controls regarding serum micronutrients (zinc and iron)

\begin{tabular}{llll}
\hline Variable & Cases, $\mathrm{n}=105$ & Controls, $\mathrm{n}=100$ & $\mathrm{p}$-value \\
\hline Zinc $(\mu \mathrm{g} / \mathrm{dl})$ & & & \\
$\quad$ Median & 80.8 & 107.3 & $<0.001^{*}$ \\
$\quad$ Interquartile & $24-181$ & $46.5-168.9$ & \\
$\quad$ range $(\mathrm{IQR})$ & & & \\
$\begin{array}{l}\text { Iron }(\mu \mathrm{g} / \mathrm{dl}) \\
\quad \text { Median }\end{array}$ & 72 & 110.45 & $<0.001^{*}$ \\
$\quad$ IQR & $20.5-189.8$ & $16.9-202.3$ & \\
\hline${ }^{*} \mathrm{p}<0.05$ significant. & & &
\end{tabular}

respectively), while MPO level did not show a significant difference between our studied groups ( $p=0.276)$.

Table 3: Comparison between cases and controls regarding fecal markers (AAT, NEO, and MPO)

\begin{tabular}{llll}
\hline Variable & Cases, $\mathrm{n}=105$ & Controls, $\mathrm{n}=100$ & $\mathrm{p}$-value \\
\hline AAT $(\mathrm{ng} / \mathrm{ml})$ & & & \\
Median & 9 & 6.2 & $0.012^{*}$ \\
IQR & $2.6-28$ & $1.5-22$ & \\
NEO $(\mathrm{pmol} / \mathrm{ml})$ & & & \\
$\quad$ Median & 21 & 19 & $0.021^{*}$ \\
IQR & $10-92$ & $11-35$ & \\
MPO $(\mathrm{ng} / \mathrm{ml})$ & & 1.75 & 0.276 \\
Median & 2.2 & $0.72-5.6$ & \\
IQR & $0.65-8.4$ &
\end{tabular}

MPO correlated positively with AAT and NEO ( $p<0.001)$, while it correlated negatively with weight, height, and BMI ( $p<0.001,0.002$, and 0.029, respectively). A significant positive correlation was noticed between NEO level and both AAT and MPO levels. On the contrary, a significant negative correlation was observed between NEO level and both WAZ and HAZ scores ( $p=0.002,0.032$, respectively). AAT had significant negative correlation with weight, height, WAZ, and HAZ scores $(p<0.001,<0.001,0.009,0.002$, respectively). Zinc showed positive correlation with both WAZ and HAZ scores ( $p=0.02)$ (Tables 4 and 5).

Table 4: Correlation of anthropometric parameters with both serum micronutrients and fecal markers

\begin{tabular}{|c|c|c|c|c|c|}
\hline Variable & Zinc $(\mu \mathrm{g} / \mathrm{dl})$ & Iron $(\mu \mathrm{g} / \mathrm{dl})$ & AAT $(\mathrm{ng} / \mathrm{ml})$ & NEO $(\mathrm{pmol} / \mathrm{ml})$ & MPO (ng/ml) \\
\hline \multicolumn{6}{|l|}{ Weight } \\
\hline$r$ & -0.038 & 0.023 & $-0.344^{*}$ & -0.146 & $-0.323^{*}$ \\
\hline $\mathrm{p}$ & 0.699 & 0.817 & 0.000 & 0.137 & 0.001 \\
\hline \multicolumn{6}{|c|}{ Weight $Z$ score } \\
\hline$r$ & $0.227^{*}$ & -0.032 & $-0.255^{\star}$ & $-0.302^{*}$ & -0.049 \\
\hline $\begin{array}{c}\mathrm{p} \\
\text { Height }\end{array}$ & \multicolumn{4}{|c|}{ Height } & 0.621 \\
\hline$r$ & -0.072 & -0.009 & $-0.343^{*}$ & -0.115 & $-0.294^{*}$ \\
\hline $\mathrm{p}$ & 0.465 & 0.929 & 0.000 & 0.241 & 0.002 \\
\hline \multicolumn{6}{|c|}{ Height $Z$ score } \\
\hline$r$ & $0.226^{*}$ & -0.133 & $-0.296^{*}$ & $-0.209^{*}$ & -0.070 \\
\hline $\mathrm{p}$ & 0.020 & 0.176 & 0.002 & 0.032 & 0.481 \\
\hline \multicolumn{6}{|l|}{ BMI } \\
\hline $\mathrm{r}$ & 0.095 & 0.042 & -0.181 & -0.191 & $-0.213^{*}$ \\
\hline $\mathrm{p}$ & 0.336 & 0.669 & 0.064 & 0.051 & 0.029 \\
\hline \multicolumn{6}{|l|}{ BMI Z } \\
\hline$r$ & 0.017 & 0.020 & -0.096 & -0.159 & -0.142 \\
\hline $\mathrm{p}$ & 0.860 & 0.837 & 0.328 & 0.104 & 0.148 \\
\hline \multicolumn{6}{|c|}{ Birth weight } \\
\hline$r$ & 0.004 & -0.108 & -0.155 & -0.024 & -0.086 \\
\hline $\mathrm{p}$ & 0.969 & 0.272 & 0.115 & 0.808 & 0.385 \\
\hline \multicolumn{6}{|c|}{ Arm circumference } \\
\hline $\mathrm{r}$ & -0.094 & 0.070 & -0.190 & -0.051 & -0.148 \\
\hline $\mathrm{p}$ & 0.342 & 0.481 & 0.052 & 0.606 & 0.131 \\
\hline
\end{tabular}
NEO: Neopetrin, MPO: Myeloperoxidase.

Multiple Linear regression analysis for factors affecting WAZ (at level of <-2) was done among malnourished children. It showed that NEO, AAT, MPO, and zinc are factors affecting WAZ, respectively ( $p=0.018,0.022,0.028$, and 0.047 , respectively) (Table 6). 
Table 5: Correlation of fecal markers with each other and serum micronutrient (iron and zinc)

\begin{tabular}{|c|c|c|c|c|c|}
\hline Variable & Zinc & Iron & AAT & NEO & MPO \\
\hline \multicolumn{6}{|l|}{$\overline{\text { AAT }}$} \\
\hline$r$ & -0.019 & 0.025 & 1 & $0.500^{*}$ & $0.674^{*}$ \\
\hline p & 0.845 & 0.802 & & 0.000 & 0.000 \\
\hline \multicolumn{6}{|l|}{ NEO } \\
\hline$r$ & 0.022 & 0.049 & $0.500^{*}$ & 1 & $0.375^{\star}$ \\
\hline$p$ & 0.821 & 0.621 & 0.000 & & 0.000 \\
\hline \multicolumn{6}{|l|}{ MPO } \\
\hline$r$ & -0.011 & 0.025 & $0.674^{*}$ & $0.375^{*}$ & 1 \\
\hline$p$ & 0.908 & 0.798 & 0.000 & 0.000 & \\
\hline
\end{tabular}

Multiple Linear regression analysis for factors affecting HAZ (at level of <-2) was done among malnourished children. It showed that AAT, zinc, and MPO are factor affecting HAZ, respectively $(p=0.004$, 0.010 , and 0.042 , respectively) (Table 7 ).

Table 6: Multiple Linear regression analysis for factors affecting weight $Z$ score (at level of <-2) among cases

\begin{tabular}{|c|c|c|c|c|c|}
\hline \multirow[t]{2}{*}{ Model } & \multicolumn{2}{|c|}{$\begin{array}{l}\text { Unstandardized } \\
\text { Coefficients }\end{array}$} & \multirow{2}{*}{$\begin{array}{l}\text { Standardized } \\
\text { Coefficients } \\
\text { Beta }\end{array}$} & \multirow[t]{2}{*}{$t$} & \multirow[t]{2}{*}{ Sig. } \\
\hline & $\mathrm{B}$ & Std. Error & & & \\
\hline (Constant) & -2.001 & 0.282 & & -7.105 & 0.000 \\
\hline Zinc & 0.004 & 0.002 & 0.184 & 2.008 & 0.047 \\
\hline Iron & -0.001 & 0.002 & -0.035 & -0.379 & 0.706 \\
\hline AAT & -0.033 & 0.014 & -0.307 & -2.323 & 0.022 \\
\hline NEO & -0.009 & 0.004 & -0.254 & -2.406 & 0.018 \\
\hline MPO & 0.101 & 0.045 & 0.275 & 2.226 & 0.028 \\
\hline
\end{tabular}

\section{Discussion}

There is a mass need for using simple, cheap, and non-invasive biomarkers for assessing intestinal permeability and inflammation. This study was undertaken to clarify the value of fecal markers of epithelial damage AAT and intestinal inflammation (MPO and NEO), as well as to assess their correlation with anthropometric measures and micronutrient status (zinc and iron) in underweight and stunted children. To fulfill this purpose, a total of 205 children were involved in this study. They were categorized into two groups: Control group ( $\mathrm{n}=100$ children) and case group ( $n=105$ children) according to criteria for diagnosis of underweight and stunted children.

Table 7: Multiple Linear regression analysis for factors affecting height $Z$ score (at level of $<-2$ ) among cases

\begin{tabular}{|c|c|c|c|c|c|}
\hline \multirow[t]{2}{*}{ Model } & \multicolumn{2}{|c|}{$\begin{array}{l}\text { Unstandardized } \\
\text { Coefficients }\end{array}$} & \multirow{2}{*}{$\begin{array}{l}\text { Standardized } \\
\text { Coefficients } \\
\text { Beta } \\
\end{array}$} & \multirow[t]{2}{*}{$\mathrm{t}$} & \multirow[t]{2}{*}{ Sig. } \\
\hline & $B$ & Std. Error & & & \\
\hline (Constant) & -2.031 & 0.287 & & -7.074 & 0.000 \\
\hline Zinc & 0.006 & 0.002 & 0.237 & 2.614 & 0.010 \\
\hline Iron & -0.004 & 0.002 & -0.145 & -1.601 & 0.113 \\
\hline AAT & -0.044 & 0.015 & -0.390 & -2.975 & 0.004 \\
\hline NEO & -0.004 & 0.004 & -0.107 & -1.023 & 0.309 \\
\hline MPO & 0.095 & 0.046 & 0.253 & 2.064 & 0.042 \\
\hline
\end{tabular}

In our study, the cases were $44.8 \%$ males and $55.2 \%$ females and the controls were $46 \%$ males and $54 \%$ females reflecting more females affection by malnutrition and stunting, but without significant difference between our two studied groups ( $p=0.859$ ).
A previous study recorded similar results $(47 \%$ males and $53 \%$ females) of their malnourished children [14]. Furthermore, in studies of Fahim et al. [8] and Perin et al. [15], males represented $50 \%$ of affected children. Non-significant difference was observed between age of our cases and controls, so both groups were age matched $(p=0.85)$.

A highly significant difference was recognized between the two studied groups regarding all anthropometric parameters (weight, height, BMI, WAZ score, HAZ score, BMI score, and arm circumference) with higher mean values in controls $(p<0.001)$. A study done by Meheta et al. [16] determined that chronic malnutrition is assessed by weight for height (WFH) and BMI SD scores lower than -2, while a study done by Dereje et al. [17] found that WAZ and arm circumference are the most important indicators of acute malnutrition in children aged between 6 and 59 months. Most anthropometric parameters were affected in a previous study done by Lindenmayer et al. [18] who assessed the relation between chronic intestinal inflammation and stunting.

The level of serum zinc and iron in our research displayed significant increase in the controls in comparison to the cases $(p<0.001)$. The previous researches revealed that serum zinc showed a significant difference between non-malnourished children and other children affected with mild to severe growth deficits [19], [20]. Bains et al. [21] recorded that iron and zinc were significantly lower in children $<5$ years living in poor and rural families who suffer from malnutrition. This could be explained by decreased intake of zinc and iron in food sources, while increased demand due to rapid growth during childhood period. Zinc deficiency is a major risk factor for infections (intestinal infection, diarrhea, and pneumonia) and growth deficits among children [22]. Iron deficiency impairs cognition and linear growth as it reduces oxygen dependent cellular metabolism through decreasing hemoglobin synthesis, decreasing red blood cells synthesis and survival due to increased oxidative stress in RBC as well as increased removal by macrophages [23]. Micronutrients deficiency may play a role in EED pathogenesis, while in this situation it is not easy to determine whether EED causes micronutrients deficiency by impairing absorption and increasing gut permeability or micronutrients deficiency causes EED through ineffective intestinal lining [24].

In the current study, the fecal markers of intestinal permeability and inflammation showed that AAT and NEO had significant higher levels in cases than controls ( $p=0.012$ and 0.021 , respectively), but MPO did not differ significantly between our two studied groups. A study by Perin et al. [15] reported that the levels of AAT, NEO, and MPO were significantly higher in children with malnutrition than controls, also another study done by Prata et al. [14], found that MPO had significant higher level in children with malnutrition 
than controls. A study by Kosek et al. [5] concluded that intestinal inflammation representing increased intestinal neutrophil activity MPO, T helper 1 activity NEO, and protein losing is incorporated with growth retardation [5].

As regarding fecal markers in the present study, MPO correlated negatively with both WAZ and HAZ scores. AAT had significant negative correlation with weight, height, WAZ, and HAZ scores. The three fecal markers showed significant positive correlation with each other. Perin et al. [15] recorded that there was significant positive correlation between MPO and WFH or length Z - score, but non-significant correlation was observed between AAT, NEO, and other anthropometric measures, also those three fecal markers had non- significant correlation with each other. Iqbal et al. [25], detected that fecal MPO was associated with decreasing HAZ score. In another study done by Fahim et al. [8] demonstrated that MPO and NEO had non-significant correlation with micronutrients (zinc and iron), also fecal markers did not show any significant correlation with each other. They did not find an association between fecal levels of AAT and plasma zinc or iron; however, after adjustment with sex and age, AAT levels had significant negative correlation with iron. In a cohort study of Arndt et al. [4], elevated MPO level, but not AAT or NEO levels was associated with decreases in linear growth suggesting the predominant role of MPO as EED marker Lauer et al. [24] demonstrated that elevated fecal biomarkers of gut inflammation and altered intestinal permeability were significantly accompanied by lower hemoglobin and iron concentrations which may be suggestive of increased iron deficiency due to intestinal malabsorption.

In the current research, linear regression analysis for factors affecting WAZ (at level of <-2) was done among malnourished children presenting that higher concentrations of fecal NEO, AAT, and MPO respectively, while the lower serum zinc level was associated with underweight. Linear regression analysis for factors affecting HAZ (at level of <-2) among malnourished children showing that higher concentrations of fecal AAT and MPO, respectively, but lower zinc level was associated with stunting.

EED a disease characterized by impaired intestinal permeability/inflammation, microbial translocation and systemic inflammation, may play a significant role in micronutrient deficiencies and faltering growth in children [24], [26]. There are several mechanisms, other than malabsorption, through which EED could impair children's growth. Pro-inflammatory cytokines are proved to suppress center of hunger in the brain causing loss of appetite even the food is available [27], also they inhibit insulin-like growth factor I production [18].

\section{Conclusion}

Faltering growth associated with elevated fecal markers of intestinal permeability AAT and intestinal inflammation NEO offers support to the hypothesis that intestinal inflammation and impaired intestinal permeability are prominent contributors to growth deficits during childhood period intestinal inflammation and impaired permeability were suggested to be important components of environmental enteropathy, so our results may suppose an association between EED and growth failure. Further studies are needed to assess growth in our cases and to test the effect of micronutrients intake on growth outcomes.

\section{Acknowledgment}

The authors are thankful to the National Research Centre and The National Nutrition Institute for their full support to carry out this study.

\section{References}

1. Smith L, Haddad L. Reducing child and undernutrition: Pastdrivers and priorities for post MDG era. World Dev. 2015;68:180-204. https://doi.org/10.1016/j.worlddev.2014.11.014

2. Hassan S, Wahed WA, Eldessouki R. Nutritional status and some sociodemographic and lifestyle chracteristics among a group of rural school children in Fayoum governorate, Egypt. Egypt J Community Med. 2018;36(2):11.

3. Sania A. The contribution of preterm birth and intrauterine growth restriction to childhood undernutrition in Tanzania. Matern Child Nutr. 2015;11(4):618-63. http://doi.org/10.1111/ppe.12085 PMid:24117986

4. Arndt M, Richardson B, Ahmed T, Mahfuz M, Haque R, JohnStewart G, et al. Fecal markers of environmental enteropahty and subsequent growth in Bangaladeshi children. Am J Trop Met Hyg. 2016;95(3):694-701. http://doi.org/10.4269/ajtmh.16-0098 PMid:27352872

5. Kosek M, Haque R, Lima A, Babji S, Shrestha S, Qureshi S, et al. Fecal markers of intestinal inflammation and permeability associated with the subsequent acquisition of linear growth deficits in infants. Am J Trop Med Hyg. 2013;88(2):390-6. http:// doi.org/10.4269/ajtmh.2012.12-0549 PMid:23185075

6. Korpe PS, Petri WA. Environmental enteropathy: Critica implications of a poorly understood condition. Trends Mol Med. 2012;18(6):328-36. http://doi.org/10.1016/j. molmed.2012.04.007 PMid:22633998

7. Carne R, Jones K, Berklegy J. Environmental enteric dysfunction: An overview. Food and Nutr Bull. 2015;36(1):76-87. http://doi. org/10.1177/15648265150361S113 


\section{PMid:25902619}

8. Fahim S, Das S, Sanin K, Gazi M, Mahfuz M, Islam M, et al Association of fecal markers of environmental enteric dysfunction with zinc and iron status among children at first two years of life in Bangladesh. Am J Trop Met Hyg. 2018;99(2):489-94. http:// doi.org/10.4269/ajtmh.17-0985

\section{PMid:29893201}

9. Hossain $M$, Haque $R$, Mondal D, Mahfuz M. Ahmed A, Islam M. Undernutrition, Vitamin A and iron deficiency are associated with impaired intestinal mucosal permeability in Young Bangladesh children assessed by Lactulose/Mannitol test. PLoS One. 2016;11(12):e0164447. http://doi.org/10.1371/ journal.Pone. 016447 PMid:27906964

10. Li F, Wilkens L, Novotny R, Fialkowski M, Paulino Y, Nelson R, et al. Anthropometric measurement standardization in the US-Affiliated Pacific: Report from the children's healthy living program. Am J Hum Biol. 2016;28(3):364-71. http://doi. org/10.1002/ajhb.22796

PMid:26457888

11. World Health Organization. WHO child growth standards based on length/height, weight and age. Acta Paediatr. 2006;450(1):76-85. http://doi.org/10.1111/j.1651-2227.2006. tb02378.x

PMid: 16817681

12. Ashaat EA, Taman KH, Kholoussi N, El Ruby MO, Zaki ME, El Wakeel MA, et al. Altered Adaptive cellular immune function in a group of Egyptian children with autism. J Clin Diagn Res. 2017;11(10):SC14-7. http://doi.org/10.7860/ JCDR/2017/28124.10782

13. World Health Organization. WHO AnthroPlus for Personal Computers Manual: Software for Assessing Growth of the Worlds's Children and Adolescents. Geneva: World Health Organization; 2009.

14. Prata M, Havt H, Bolick D, Pinkertorn R, Lima A, Guerrant RL. Comparisons between myeloperoxidase, lactoferrin, calprotectin and lipocalin- 2, as fecal biomarkers of intestinal inflammation in malnourished children. J TransI Sci. 2016;2(2):134-49. http:// doi.org/10.15761/JTS.1000130 PMid:27746954

15. Perin J, Burrowes V, Almeida M, Ahmed S, Haque R, Parvin T, et al. A retrospective case control study of the relationship between the gut microbiota, enteropathy, and child growth. Am J Trop Met Hyg. 2020;103(1):520-7. http://doi.org/10.4269/ajtmh.19-0761 PMid:32431271

16. Meheta N, Corkins M, Layman B, Malone A, Goday P. Definition of pediatric malnutrition: A paradigm shift toward etiology related definitions. J Parenter Enteral Nutr. 2013;37(4):460-81. http:// doi.org/10.1177/0884533616671861

\section{PMid:30865345}

17. Dereje A, Alemayehu Y, Afework B, Alessandra B. Comparison of mid upper arm circumference and weight for height $Z$ score in identifying severe acute malnutrition among children aged between 6-59 months in South Gondar Zone, Ethiopia. J Nutr Metab. 2021;2021:8830494. https://doi. org/10.1155/2021/8830494

18. Lindenmayer G, Stoltzfus R, Prendergast A. Interaction between Zinc deficiency and environmental enteropathy in developing countries. Adv Nutr. 2014;5(1):1-6. https://doi.org/10.3945/ an.113.004838

PMid:24425714

19. Park S, Choi H, Yang H, Yim J. Effects of zinc supplementation on catch-up growth in children with failiure to thrive. Nutr Res Pract. 2017;11(6):487-91. https://doi.org/10.4162/nrp.2017.11.6.487 PMid:29209459

20. Abd El-Shaheed A, El-Arab AE, Abou-Zekri M, El Wakeel MA, El-Kassas GM, Mohsen NA, et al. A novel gluten-free meal as a nutritional therapy for Iron deficiency anemia in children with celiac disease. Biosci Res. 2018;15(1):207-14.

21. Bains K, Kaur H, Bajwa N, Kaur G, Kapoor S, Singh A. Iron and zinc status of 6-moth to 5-year- old children from low income rural familes of Punjab India. Food Nutr Bull. 2015;36(3):254-63. https://doi.org/10.1177/0379572115597396 PMid:26385949

22. Penny M. Zinc supplementation in public health. Ann Nutr Metab. 2013;62(1):31-42. https://doi.org/10.1159/00034826 PMid:23689111

23. Soliman A, De Sanctis V, Kalra S. Anemia and growth. Indian J Endocrinol Metab. 2014;18(1):S1-5. https://doi. org/10.41312230-8210.1450.8 PMid:25538873

24. Lauer J, Ghosh S, Ausman L, Webb P, Bashaasha B, Agaba E, et al. Markers of environmental enteric dysfunction are associated with poor growth and iron status in rural Ugandan infants. J Nutr. 2020;150:2715-182. https://doi.org/10.1093/jn/ nxaa141

25. Iqbal N, Sadiq K, Sayed S, Akhund T, Umrani F, Ahmed S, et al. Promising biomarkers of environmental enteric dysfunction: A prospective cohort study in Pakistani children. Sci Rep. 2018;8:2966. https://doi.org/10.1038/s41598-018-21319-8

26. El Wakeel MA, El-Kassas GM, Hashem SA, Abouelnaga MW, Elzaree FA, Hassan M, et al. Potential role of oxidative stress in childhood obesity and its relation to inflammation. Biosci Res. 2018;15(4):3791-9.

27. Sanderson I. Growth problems in children with IBD. Nat Rev Gastroenterol Hepatol. 2014;11(10):601-10. https://doi. org/10.1038/nrgastro.2014.102

PMid:24957008 